\title{
Measuring step geometry using the Nose-to- Nose method: Validity and repeatability
}

\author{
Daniel Johnson ${ }^{\mathrm{a}}$, Gary Sloan ${ }^{\mathrm{b}}$ \\ ${ }^{a}$ Daniel A. Johnson, Inc., 6221 Swayne Dr NE, Olympia, WA, 98516 U.S.A. \\ ${ }^{\mathrm{b}}$ Gary Sloan, Forensic Human Factors, 2934 Steamboat Island Northwest, Olympia, WA, 98502 U.S.A.
}

\begin{abstract}
Precise measurement of stairway geometry is important in order to establish whether a stairway meets design goals, standards and codes. The Traditional method of measuring risers and runs (goings) does not measure the stairs in the way that codes define risers and runs, and does not measure the stairs in the way users experience them. The Nose-to-Nose method does. This study was conducted to determine the validity and repeatability of this method. Two researchers used this method to study the risers and runs on two separate stairways, one carpeted and the other not. Results demonstrated a high degree of validity and repeatability.
\end{abstract}

Keywords: Stairs, risers, runs, measurement, Nose-to-Nose

\section{Introduction}

According to the US Consumer Product Safety Commission National Electronic Injury Surveillance System there has been about a 40 percent increase in falls and injuries on home stairways since the middle 1990s. Medical costs, lost productivity and loss of quality of life losses totaled US \$47 billion in 1995 [5]. There has been no concomitant increase in falls and injuries on stairs outside of private residences.

When there is a fall on a stairway a proficient forensic investigator will measure the step geometry of the entire stairway because a person who fell may not remember exactly which tread was being stepped on at the beginning of the fall.

Also, falls often occur because of variations in step geometry $[1,9]$. That is, falls are associated with differences between risers or between runs (goings) in a flight. A run is the dimension of a tread in the direction of travel and the rise is the vertical dimension: A description of the parts of the stairway, and some recommended dimensions are shown in Figure 1. Without knowing riser heights and run lengths of the other steps an investigator would not be able to determine the consistency in step geometry.

\footnotetext{
"Corresponding author. Email: dajinc1@mac.com
}

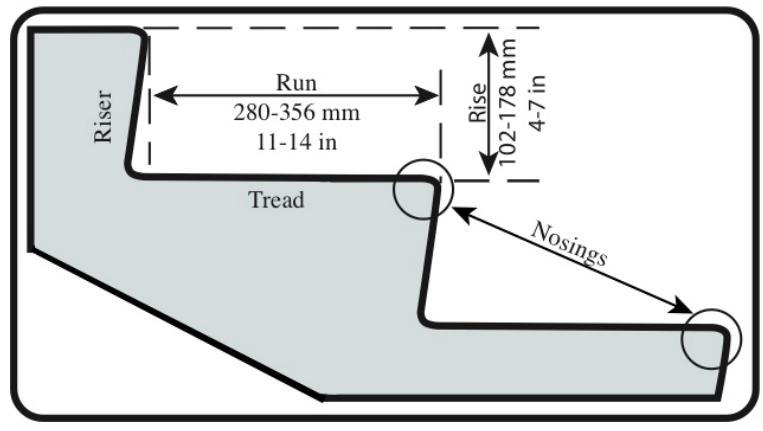

Fig. 1. Description of some of the elements of a stairway along with some recommended dimensions.

More missteps occur on steeper stairs, stairs where the risers are too high or the runs are too short. In one study subjects were tested as they ascended and descended stairs at three different slopes $(25,35$ and 45 degrees), with three different riser-to-tread ratios, and at three different speeds (slow, normal, and almost running). They wore instrumented shoes with switch- 
es so that if a certain portion of the foot didn't land on the step a "miss-step" was recorded [7].

In descent, risers with the fewest missteps ranged from $117 \mathrm{~mm}$ to $183 \mathrm{~mm}$ (4.6 in to $7.2 \mathrm{in}$ ). Risers greater than $183 \mathrm{~mm}$ (7.2 in) had a greater number of missteps. And treads that were $312 \mathrm{~mm}$ (12.3 in) or more in depth (i.e., the runs or goings) had the fewest missteps at all speeds; treads that were $269 \mathrm{~mm}$ to $292 \mathrm{~mm}$ (10.6 in to $11.5 \mathrm{in}$ ) had more missteps, followed by treads that were $254 \mathrm{~mm}$ to $262 \mathrm{~mm}$ (10.0 in to $10.3 \mathrm{in})$. All treads that were $229 \mathrm{~mm}$ (9.0 in) or less performed uniformly poorly regardless of riser height [7].

Workers were videotaped using 31 flights of stairs where there had been high frequencies of severe stairrelated injuries [9]. The investigators identified 98 stair users who experienced "incidents" (falls, slips, trips, missteps, and moments of temporary instability). Examination determined that incident rates were associated with several factors. Design factors showed that stairs with risers greater than $178 \mathrm{~mm}$ (7 in) and having tread depths less than $279 \mathrm{~mm}$ (11 in) were associated with more incidents.

More recent work also found that the foot slipping or pivoting off of a nosing could be attributed to risers that are too high or runs that are too short [10]. The investigators found that preferred runs were longer than those usually found on stairs; Runs greater than $300 \mathrm{~mm}$ (11.8 in) were optimal (they tested runs in approximate $25 \mathrm{~mm}$ (1 in) intervals from 200 $\mathrm{mm}$ to $425 \mathrm{~mm}$ (7.9 in to $16.7 \mathrm{in}$ ). Further, higher risers resulted in more of the shoe being placed further forward on the tread regardless of run length. This indicates that a foot pivoting/slipping off a tread could be due to a riser that was too high. Optimal rise height was $190 \mathrm{~mm}$ (7.5 in) and less.

The probability of a shoe slipping over the nosing, based on run length and exposure has been calculated [6]. For instance, a flight with 14 steps, and having a run of $226 \mathrm{~mm}$ ( $8.9 \mathrm{in}$ ) and being used by five people every day, would result in a slip of the foot over the nosing about once every three years. If there were 2,000 uses each day a slip would occur about every three days.

Later research showed that more falls occurred in dwellings having shorter runs than in dwellings with larger runs [11]. No falls were recorded when the dwelling had runs of 11 inches or more; below 11 inches the incidence of falls increased.

Ascertaining the height of risers and the length of runs (goings) is relatively easy if the treads are not covered. However, taking these measurements on a carpeted stairway is more difficult because the supporting structure is not open to direct measurement.

It is important that measurements be as accurate as possible because the owner of the stairway may be liable if an injury-producing fall occurs on a stairway that is either too steep or too variable. If not too steep or too variable then the cause of the fall may have occurred because of inadequate lighting, lack of maintenance, or the person's behavior. From a liability standpoint it is important that stairway measurements be of the highest precision.

Accurate measurement is also important for building officials who must inspect a new facility before issuing a license for occupancy. If the stairs are not in compliance they may need to be repaired, or perhaps even replaced before the building can be occupied. Precise measurement is the only way to ascertain if a stairway meets code as far as rise height, run length, or variability within the stairway.

The purpose of this study was to ascertain the reliability and validity of the Nose-to-Nose method for measuring stair geometry when two different investigators were taking the measurements.

\section{Uncarpeted stairs}

Using a common straight edge and their own electronic levels two researchers took independent measurements of each of 14 uncarpeted stairs that comprised an external wooden stairway at a single-family residence built in 1978 .

\section{Carpeted stairs}

The same researchers performed the same measurements on a carpeted stairway, the underlying structure of which was also built in 1978. This is the same stairway that was the subject of a previous investigation and report [3].

\section{Traditional method}

In this earlier study [3] two methods of measuring were compared. The "Traditional" method of measuring was performed with the carpet in place. In this method riser height is measured by extending a straightedge beyond an upper step and a ruler is used to measure the vertical distance from the nosing down to the next tread. Run length is measured by noting the distance between the forward edge of the tread (its nosing) and a point just below the nosing of the tread above (see Figure 2). 


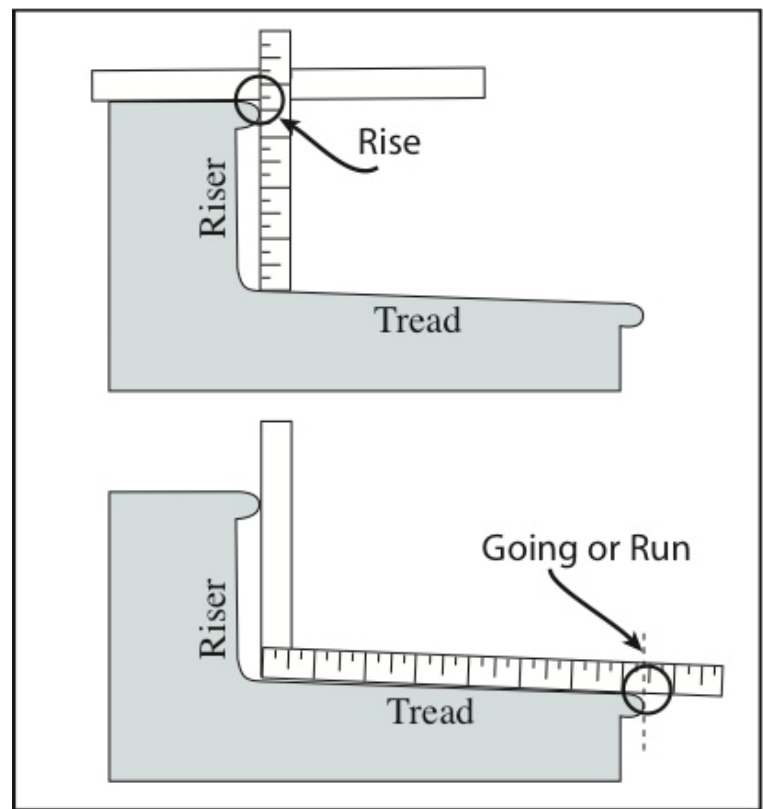

Figure 2. The Traditional method for measuring risers and runs does not measure the slope of the treads.

\section{Nose-to-Nose method}

The "Nose-to-Nose" method uses a technique suggested by Pauls [5] and developed by Johnson [3]. This method measures the distance and the angle between adjacent nosings. From these two measures, which provide the length of the hypotenuse of a right triangle and its angle from the horizontal, the rise and the run can be deduced. The sine of the angle times the distance gives the riser height and the cosine of the angle times the distance gives the run length.

Building codes [2,4] call out for the rise to be measured vertically between two adjacent nosings, not from the nosing of one step to the back of an adjacent tread which is what is measured by the Traditional method. And the run is the horizontal distance between the vertical planes of the foremost projection of adjacent nosings, and at a right angle to the step's leading edge (see Figure 3).

The Traditional method of measuring step geometry would only be accurate if there were no slope to the tread. But treads often slope as a result of wear or through design. For instance, on external stairs one may find that treads have a "wash", "a slope to throw water off the tread during rain (and to prevent ice formation)". And even some interior stairs were sloped slightly in an effort to ease the comfort of the stair user [8].

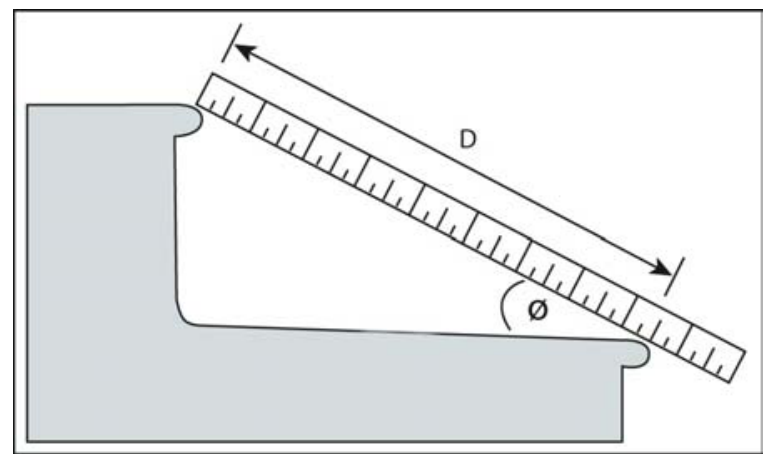

Figure 3. The Nose-to-Nose method measures the distance between nosings and the slope directly.

If there were a slope the difference between measurement techniques can be significant. Slope invalidates the rise height when measured by the Traditional method. If the slope were say, not-an-unheard-of $6^{\circ}$, then over a $280 \mathrm{~mm}(11 \mathrm{in})$ run the difference between the rise height as measured at the back of the tread and at the front, where it should be measured and where it is experienced, would be $\left(\tan 6^{\circ} * 280\right.$ $\mathrm{mm}=) 29 \mathrm{~mm}(1.1 \mathrm{in})$. Sloping of the tread can also affect the measured run length, as pointed out elsewhere [3].

\section{Purpose of current study}

\subsection{Reliability}

One purpose of this study was to determine the reliability of the Nose-to-Nose method by comparing the data recorded independently by two researchers. If the differences between the measurements taken by the two researchers are not significantly different then the method can be considered reliable.

\subsection{Validity}

Another purpose of this study was to see if the two researchers, using the Nose-to-Nose method, could reliably measure the geometry of the supporting underlying structure. This would be determined by comparing the current measurements of the carpeted stairway with the measurements taken of the uncarpeted stairway eight years earlier [3]. If the current measurements are not significantly different from those taken in 2003 then the method could be considered valid. 


\section{Procedure}

Measurements were taken midway between the sidewalls of the two stairways. On the wooden stairs the measurements were made and the results recorded.

On the carpeted stairs a straight pin, with a large head so that adequate finger pressure could be applied to the pin, was pushed through the carpet pile and the underlying carpet pad. The pin was pushed through near the edge of the nosing that could be felt with the fingers. Pushing the pin resulted in it stopping when the pin contacted the underlying solid surface of the tread.

The pin was then moved toward the edge of the nosing in increments of about $1 \mathrm{~mm}$ until the pin was felt to go through the pile and pad without contacting the underlying structure. The pin was then extracted and moved back toward the nosing and pushed down so that it was felt to just graze the forward-most edge of the nosing. It was left in this position. The same procedure was conducted on an adjacent tread.

\subsection{Between tread distance}

A ruler was used to ascertain the distance between the bases of the two straight pins (see Figure 4). The distance, in $\mathrm{mm}$, was recorded.

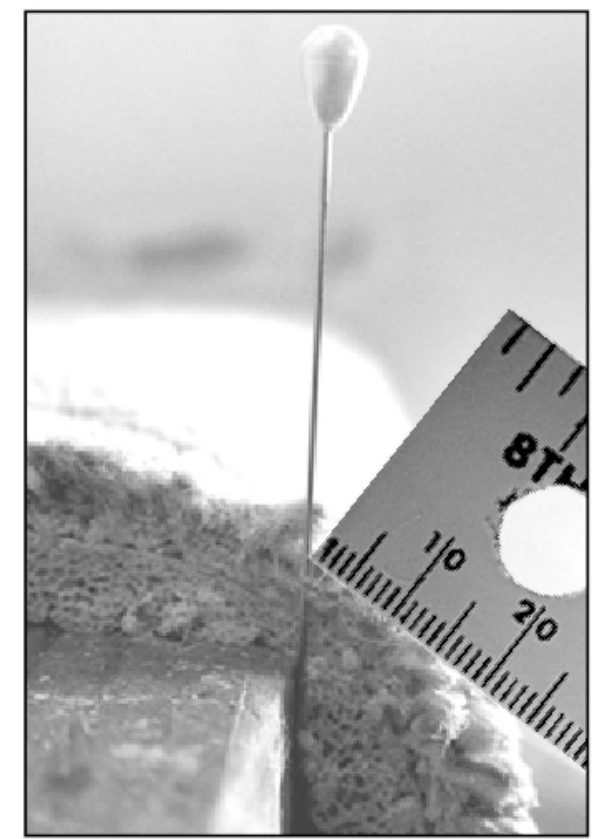

Figure 4. The distance between the base of the pins, and the slope between the adjacent nosings, were measured.

\subsection{Slope between nosings}

The two researchers measured the slope between each pair of adjacent nosings. The $610 \mathrm{~mm}$ (24 in) long levels were calibrated prior to the start of the tests. The slope was measured with each researcher's own electronic level $\left(\right.$ SmartTool $\left.^{\circledR}\right)$ that has an accuracy to \pm 0.1 degree.

The level was held down on the nosings of the uncarpeted stairs and the angle recorded. On the carpeted stairs the level was placed next to the two straight pins, and enough pressure was applied by hand to ensure the level was firmly supported by the underlying wooden tread. The level was held in place until a stable reading on the level was obtained, then recorded.

\subsection{Slope of each tread}

Although not needed to determine the rise height and run lengths of the various treads using the Nose-toNose method, the slope of both wooden and carpeted treads were measured. The purpose was to ascertain how much, and in which direction, the treads sloped from front to back. The electronic level was pushed down on each carpeted tread until a stable reading was attained.

\section{Results}

\subsection{Reliability}

The difference in distance measurements by the two researchers on the wooden steps averaged $1.8 \mathrm{~mm}$ $(<0.01 \mathrm{in})$ with a range 0 to $3 \mathrm{~mm}$ ( 0 to $0.1 \mathrm{in})$. A t test showed the difference was not statistically significant $(\mathrm{p}=0.79)$.

The difference in distance measurements by the two researchers on the carpeted steps also averaged $1.8 \mathrm{~mm}(<0.01 \mathrm{in})$ with a range of 0 to $5 \mathrm{~mm}(0$ to 0.2 in). A t test showed the difference was not statistically significant $(\mathrm{p}=0.92)$.

The average difference between the Nose-to-Nose slopes measured by the researchers on the wooden steps was 0.14 degrees (range $=0$ to 0.3 degrees). A t test showed the difference was not statistically significant $(\mathrm{p}=0.28)$.

The average difference between the Nose-to-Nose slopes measured by the researchers on the carpeted steps was 0.18 degrees (range $=0^{\circ}$ to $0.6^{\circ}$ ). A t test 
found the difference was not statistically significant $(\mathrm{p}=0.92)$.

\subsection{Slope (wash) of treads}

All of the wooden treads sloped downward from back to front at an average angle of $0.8^{\circ}$ (range $=0.1^{\circ}$ to $\left.1.7^{\circ}\right)$. All of the carpeted treads sloped downward from back to front at an average angle of $3.5^{\circ}$ (range $=1.8^{\circ}$ to $4.5^{\circ}$ ). On both stairways some of the treads had two slopes; one in the back, near the riser, and another, usually a steeper slope, closer to the nosing.

Since tread slopes would not have been detected using the Traditional method the average riser height using the Traditional method would have been different than the riser height measured by the Nose-toNose method. For instance, on the carpeted tread that was found to slope down 4.5 degrees the Nose-toNose method would have indicated a riser height (tan $\left.4.5^{\circ} * 280 \mathrm{~mm}=\right) 22 \mathrm{~mm}$ (0.9 in) greater than indicated if measured by the Traditional method.

According to some codes $[2,4]$ the maximum variation between riser heights within a flight must not exceed $9.5 \mathrm{~mm}\left(0.375^{\prime \prime}\right)$. The error of $22 \mathrm{~mm}$ ( $\left.0.9 \mathrm{in}\right)$ caused by using the Traditional method exceeded the allowable variation by over 200 percent.

\subsection{Effect of instrument / operator variability on measured tread dimensions}

The riser height of each tread was determined using each researcher's data: (sin angle * distance). Both researchers found the average riser height on the 14 wooden stairs to be $179 \mathrm{~mm} \pm 0.5 \mathrm{~mm}(7.05 \pm$ 0.02 in). The average difference between the researcher's measurements of the risers was $0.47 \mathrm{~mm}$ ( 0.02 in). The correlation, $r$, between their riser measurements was 0.97 .

Run lengths (cosine angle * distance) were calculated. Both researchers found the average run length for the wooden treads to be $259.4 \mathrm{~mm} \pm 0.5 \mathrm{~mm}$ (10.2 in $\pm .02 \mathrm{in}$ ). The average difference between the researcher's measurements of the runs was $1.1 \mathrm{~mm}$ (0.04 in). The correlation between their run measurements was 0.98 .

Both researchers found the average riser height on the 12 carpeted treads to be $211.4 \pm 0.5 \mathrm{~mm}(8.32 \pm$ $0.02 \mathrm{in})$. The average difference between the researcher's measurements of the risers was $1.5 \mathrm{~mm}$ (0.06 in). The correlation between their riser measurements was 0.91 .
Both researchers found the average run length for the carpeted treads to be $277.5 \pm 0.14(10.9 \pm 0.01 \mathrm{in})$. The correlation between their run measurements was 0.95 .

\subsection{Confidence intervals}

If a measured carpeted riser were found to be 210 $\mathrm{mm}(8.3 \mathrm{in})$ there is a $95 \%$ probability the true riser would be $(209.8 \mathrm{~mm}<210 \mathrm{~mm}<210.2 \mathrm{~mm})(8.26$ in $<8.27$ in $<8.28$ in).

Likewise, if a measured carpeted run were found to be $279 \mathrm{~mm}(11 \mathrm{in})$ there is a $95 \%$ probability the true run would be $(278.9 \mathrm{~mm}<279 \mathrm{~mm}<279.1 \mathrm{~mm})$ (10.9 in $<11$ in $<11.1$ in).

The high levels of accuracy and replicability found here are due, in part, to the fact that any reading and measurement errors are spread over the combined calculation of the rise heights and run lengths.

\subsection{Validity}

One researcher had measured the carpeted stairs in 2003, and again during the current tests. His slope readings for these two correlated, $r=0.98$. The other researcher's slope readings were not significantly different from the original measurements taken by the other researcher eight years prior; the average slope difference between adjacent nosings was 0.2 degrees. The correlation between the earlier slope measurements and the later ones, taken by the different researchers, was 0.99 .

With but one exception the distance between the nosings also showed no significant changes. The average distance between nosings in 2003 was 349.1 $\mathrm{mm}$ (13.7 in), the same as found by both researchers in 2011 . The readings by both researchers correlated $(r=0.84)$ with the readings obtained 7 years earlier.

The $\mathrm{t}$ tests indicated there were no significant changes in the carpeted step geometry over this period with one exception; that was between the bottom two nosings. When measured in 2003 the distance was $352 \mathrm{~mm} \pm 1.5 \mathrm{~mm}$ (13.86 in $\pm 0.06 \mathrm{in})$. In 2011 the two researchers found it to be $338 \mathrm{~mm} \pm$ $1.5 \mathrm{~mm}$ (13.31 in $\pm 0.06 \mathrm{in})$. Although the reason for this anomaly is unclear, it may be that since the bottom tread was wood, those transitioning from or to the bottom landing wore away the underlying structure of the nosing.

The high reliability of these findings may not hold if there are relatively large variations across the width of the stair nosings. If there were portions of the nos- 
ings that had worn away, for instance, then the distance and slope measurements between adjacent treads could be different, depending on placement of the tools. Some experience in using the techniques described in this document and in [3] would be helpful in achieving the ability to perform accurate measurements reliably.

\section{Conclusions}

The Nose-to-Nose method is a reliable method in that different investigators using this technique should come up with virtually the same results for a given set of treads.

The Nose-to-Nose method provides a direct measure of the height of one nosing over an adjacent nosing, as defined by codes and standards, and as experienced by the user.

The Nose-to-Nose method also provides the run length as defined by codes and standards, and as experienced by the user.

The measurements using the Nose-to-Nose method provide a valid description of the underlying supporting structure of a carpeted stairway. There may be some wear to the underlying structure over a period of years.

Research has shown that the Traditional method gives results that are different from the Nose-to-Nose method and, therefore, different from the way the supporting structure of the stair is constructed; different from the way codes and standards define riser height and run length; and different from the way in which the user experiences the stairway. Those wishing to determine with accuracy the step geometry of a stairway should not use the Traditional method.

\section{References}

[1] Cohen, J., LaRue, C. A., and Cohen, H. H. (2009). An ergonomics analysis of 80 cases. Professional Safety, 54, 27-41.

[2] IBC International Building Code (2012). Falls Church, VA: International Code Council.

[3] Johnson, D. A. (2005, Spring). Error in stair measurement. Ergonomics in Design. Santa Monica, CA: Human Factors and Ergonomics Society. Reprinted in By Design, 2005 Summer 5(1). Des Plaines, Illinois: American Society of Safety Engineers.

[4] LSC, Life Safety Code Handbook. (2012). Quincy, MA National Fire Protection Association.

[5] Pauls, J. L. and Harbuck, S. C. (2008). Ergonomics-based Methods of Inspecting, Assessing and Documenting Environmental Sites of Injurious Falls. Presented at American
Society of Safety Engineers. Downloaded10/24/2008 www.asse.org/education/pdc08/show-session.php?id=704

[6] Roys, M and Wright, M. (2003.) Proprietary nosing for non-domestic stairs. Information paper 15/03, BRE Centre for Human Interaction, Garston, Watford UK WD25 9XX. Website: www.bre.co.uk

[7] Templer, J. A. (1974). Stair shape and human movement Ann Arbor, MI: U.M.I. Dissertation Information Service.

[8] Templer, John (1992). The staircase: studies of hazards, falls and safer design. Cambridge, MA: MIT Press.

[9] Templer, J., Archea, J. and Cohen, H. (1985). Study of factors associated with risk of work-related stairway falls. Journal of Safety Research, 6, 183-196.

[10] Wright, M. and Roys, M. (2005). Effect of changing stair dimensions on safety. Contemporary Ergonomics 2005. New York: Taylor and Francis. 469-474.

[11] Wright, M. and Roys, M. (2008). Accidents on English dwelling stairs are directly related to going size. In Bust, P.D. (ed.) Contemporary Ergonomics 2008. New York: Taylor and Francis. 632-637. 